\title{
Analysis of the Prevalence of Canine Toxocariasis in Matilde Esther, Ecuador, and its Connotation in Human Health
}

\section{Jorge Luis Sánchez Palomino*, Hugo Javier Alvarado Álvarez, Lidia Leonor Paredes Lozano, Gustavo Adolfo Vásconez Galarza and Ketty Beatriz Murillo Cano}

Department of Facultad de Ciencias Agropecuarias, Faculty of Agricultural Sciences, Universidad Técnica de Babahoyo, Technical University of Babahoyo, Ecuador

*Corresponding Author: Jorge Luis Sánchez Palomino, Department of Facultad de Ciencias Agropecuarias, Faculty of Agricultural Sciences, Universidad Técnica de Babahoyo, Technical University of Babahoyo, Ecuador.

DOI: 10.31080/ASVS.2022.04.0324
Received: February 01, 2022

Published: February 15, 2022

(C) All rights are reserved by Jorge Luis

Sánchez Palomino., et al.

\begin{abstract}
Toxocariasis is an invasive, zoonotic and cosmopolitan disease, produced by the biological etiological agents Toxocara canis and Toxocara cati. The objective of this research is to give the value that this topic deserves for human health, by investigating its prevalence in Matilde Esther, Ecuador; It was carried out during the months of September-December 2021; 110 canines were investigated, evaluating the variables, ages, sexes, races, origin, type of feeding, related to the disease, randomly, without discrimination, considering the study, observational, epizootiological, non-probabilistic, applying a non-experimental, descriptive, prospective design, cross; The data were weighted through contingency tables, using the Chi square statistic, plus the SPSS statistical program, where the prevalence of parasites was demonstrated, facilitating their multiplication and development, increasing the risk of damage in humans, in a revealing and alarming.
\end{abstract}

Keywords: Canines; Cosmopolitan; Infestation; Nematodes; Syndrome; Zoonoses

\section{Abbreviations}

RPM: Revolutions Per Minute; HOF: Helminth Ovoscopic Flotation Technique; ML: Milliliters; SPSS: Statistical Program

\section{Introduction}

Toxocariasis is an invasive, zoonotic and cosmopolitan disease, produced by the biological etiological agents Toxocara canis and Toxocara cati.

Among the pets that live with man, the dog occupies the first place and is considered the best friend, especially of children, and without hesitation this harmony is affected by the presence of parasitic diseases that cause acute or chronic clinical pictures that affect health, vitality and physical appearance and that can cause death [5].
Since the human being is not the definitive host of the nematode, its larvae do not mature in the body, allowing them to migrate erratically throughout the body through the blood to different systems and organs, given their prolificacy and the great resistance of their eggs. to environmental conditions [16]; Depending on the organs that are invaded, the time of migration, the intensity of the invasion, the age of the patient and the immune response presented by the host, inflammatory reactions known as visceral larval migration syndrome are produced, with symptoms of fever, leukocytosis, hepatosplenomegaly, bronchitis, adenopathies, joint pain, encephalitis or meningitis, intracranial tumor, among other manifestations.

A change in inadequate hygienic and sanitary habits is required. Participatory methodologies aimed at health education promoted 
by the WHO [10], based on raising the essential attributes and capabilities of people to stimulate behavior change, their strength and inventiveness, action planning.

Over the years, these diseases have caused more deaths and economic damage to human beings than all armed conflicts combined, in turn, it is considered the most important parasitic zoonosis today, so we have set ourselves the goal through this research to analyze its prevalence in Matilde Esther, Ecuador.

\section{Materials and Methods}

The research was carried out in the months of September to December 2021, in Matilde Esther, Ecuador. 110 canines were studied, collecting the results of the variables age, sex, race, origin and food received, randomly, without discrimination; Then, the inductive method was applied for the macroscopic observation of feces, the presence of non-embryonated eggs, microscopic observation, weighting, concentration, sedimentation and flotation, using the Helminth ovoscopic flotation (HOF) technique. Data were weighted using contingency tables, using the Chi square statistician, plus the statistical program SPSS.

\section{Materials used for the HOF technique}

Canine stool samples, plastic cups and spoons, fine mesh strainers, coverslips and slides, centrifuge, test tubes, racks, supersaturated saline solution, microscope, gloves, rectal cannula, box of plastic to obtain the sample, field sheet (registration), pen, pipette, covers, alcohol, flannel, detergent.

\section{Procedure used to perform the technique in canines}

Five to ten grams of feces were taken from different parts of the sample. Saline solution is added to obtain a volume of $100 \mathrm{~mL}$, the fecal suspension is sieved using a fine mesh strainer. Three-fourths of the test tube is filled. It is placed in the centrifuge for three minutes at $2000 \mathrm{rpm}$. After centrifugation, two or three drops of the supernatant are obtained with a pipette and placed on the slide. Observed under a microscope with a 10x objective.

\section{Experimental procedure}

We consider that this research is non-probabilistic epizootiological observational, with a universe of 110 randomly selected canines, through a non-experimental, descriptive, prospective, crosssectional design.
This formula was applied

Prevalence: Number of cases with the disease at a given time/ Total population at that time $\times 100$

Prevalence: $58 / 110 \times 100=52.72 \%$.

\section{Results and Discussion}

The universe of the sample was 110 canines; Table 1 shows the significant percentage of positive cases for Toxocariasis of $52.72 \%$, revealing its prevalence, information obtained with the technique, HOF; Similar studies carried out and positive cases have shown, but to a lesser extent, 47.28\% (Ancylostomas 24.9\%, Ascaris 8.1\%, American Necátor 6.5\%, Trichuris vulpis $4.1 \%$, and Dipylidium caninum 3.68\%). According to the World Health Organization [18], Toxocariasis is widely distributed worldwide, being endemic in most of the countries of America, Africa and Asia. The prevalence of this infection is difficult to establish due to the difficulty of an accurate diagnosis and the fact that this disease is not notifiable. Man is an accidental host, with children being the most affected due to their playing habits in parks and backyards contaminated with parasite eggs [6].

\begin{tabular}{|l|c|}
\hline Parasites & Prevalence \\
\hline Toxocara canis & $52.72 \%$ \\
\hline Others & $47.28 \%$ \\
\hline
\end{tabular}

Table 1: Prevalence of Toxocara canis in the analyzed population $(\mathrm{n}=110) . * *$

** of our authorship.

Table 2 indicates the result by sex, with $62.72 \%$ preponderating the infested females, with the biological etiological agent investigated. These authors [1] concluded that male and female canines of any sex, from 20 days to a year and females older than 1 year in heat, pregnancy or lactation, act as disseminators of Toxocariasis.

\begin{tabular}{|l|c|c|}
\hline Sex & Patients & Percentage \\
\hline Females & 69 & 62.72 \\
\hline Males & 41 & 37.28 \\
\hline Total & 110 & 100.00 \\
\hline
\end{tabular}

Table 2: Prevalence of Toxocara canis in dog feces, according to their sex. **

** of our authorship. 
Table 3 denotes the score by age, where patients 45 days to 1 year old predominate, infested with the biological etiological agent under study with $53.64 \%$, followed by the age group of 1 to 3 years old that reached $28.18 \%$, coinciding with [14], stating that Toxocara canis is an intestinal cosmopolitan nematode that seriously affects puppies and frequently adult canids.

\begin{tabular}{|l|c|c|}
\hline Ages & Canine & Percentage \\
\hline 45 days to 1 year & 59 & 53.64 \\
\hline 1 to 3 years & 31 & 28.18 \\
\hline 3 to 5 years & 14 & 12.74 \\
\hline 5 to 7 years & 5 & 4.54 \\
\hline 7 to 9 years & 1 & 0.90 \\
\hline More than 9 years & 0 & 0 \\
\hline Total & 110 & 100.00 \\
\hline
\end{tabular}

Table 3: Prevalence of Toxocara canis in dog feces, according to their ages. ${ }^{* *}$

** of our authorship.

Table 4 presents the score by breed, where mestizo canines infested with the biological etiological agent under investigation prevail with $48.20 \%$, followed by the Pitbull and Poodle breeds with $25.45 \%$ and $10.0 \%$ respectively, Rottweiler with $8.18 \%$, Boxer with 4.54\% and Cocker Spaniel with 3.63\%; similar results were obtained at the conclusion, that the highest incidence rate of Toxocara canis in canine feces was found in the mestizo breed with $27.7 \%$, followed by the Pitbull breed with $4.5 \%$, then the French Poodle breed with $1.4 \%$, Rottweiler with $1.4 \%$, and the Cocker, German Shepherd, Sausage, Dogo with $0.28 \%$ of positive cases. [17].

\begin{tabular}{|l|c|c|}
\hline Breeds & Patient & Percentage \\
\hline Mongrels & 53 & 48.20 \\
\hline Pitbull & 28 & 25.45 \\
\hline Poodle & 11 & 10.00 \\
\hline Rottweiler & 9 & 8.18 \\
\hline Boxer & 5 & 4.54 \\
\hline Cocker Spaniel & 4 & 3.63 \\
\hline Total & 110 & 100.00 \\
\hline
\end{tabular}

Table 4: Prevalence of Toxocara canis in dog feces, according to breed. **

** of our authorship.
Table 5 expresses the scores according to their origins, where gift canines predominate, infested with the biological etiological agent under investigation, with $53.63 \%$, followed by those collected from the street with $28.20 \%$; reached a similar result, when he found the highest percentage of incidence of Toxocara canis in canine feces was in patients collected from the street, with $27.5 \%$ [14].

\begin{tabular}{|l|c|c|}
\hline Origins & Patient & Percentage \\
\hline Given away & 59 & 53.63 \\
\hline Picked up from the street & 31 & 28.20 \\
\hline Purchased & 12 & 10.90 \\
\hline Born at home & 8 & 7.27 \\
\hline Total & 110 & 100.00 \\
\hline
\end{tabular}

Table 5: Prevalence of Toxocara canis in canine feces, according to its origins. ${ }^{* *}$

** of our authorship.

Table 6 reveals the scores according to the type of food they receive, where dogs that consume pellets and homemade food predominate with $50.93 \%$.

\begin{tabular}{|l|c|c|}
\hline Feeding & Patient & Percentage \\
\hline Pellets and homemade food & 56 & 50.93 \\
\hline Pellets & 34 & 30.90 \\
\hline Homemade food & 14 & 12.72 \\
\hline Homemade food leftovers & 6 & 5.45 \\
\hline Total & 110 & 100.00 \\
\hline
\end{tabular}

Table 6: Prevalence of Toxocara canis in dog feces, according to the type of food they receive. ${ }^{* *}$

** of our authorship.

\section{Conclusions}

- The existence of Toxocara canis is ratified in 58 of the 110 canines analyzed by the Helmito ovoscopic flotation technique, evidencing its prevalence.

- $62.72 \%$ of positive cases are female.

- $48.20 \%$ of the positive cases to the biological etiological agent under investigation are mestizo canines.

- There was no statistical significance between the variables studied, with the existence of a biological etiological agent, so 
according to this research, all canines have the same probability of suffering and transmitting the disease.

- The poor health conditions in areas of the studied area are predisposing factors for the existence, multiplication and development of the biological etiological agent.

- There is no culture about the dangers of this disease in the human population in the investigated area.

\section{Recommendations}

Provide adequate health education to the population, deworming and timely veterinary control of pets and promote the correct washing of hands and food, in all people.

\section{Conflict of Interest}

There were no conflicts in the development of the study.

\section{Bibliography}

1. Bojanich MV and Lopez MA. "Toxocara Canis under the magnifying glass". Magazine. Argentina. Microbiology 41.1 (2009).

2. Castillo Duarte and Morales. "Prevalence and risk factors associated with Toxocara canis and Ancylostoma caninum infection in companion dogs". Neotropical Parasitology (2016).

3. Guarin C. "Situation of Toxocariasis in some Latin American countries: Systematic review (master's thesis). National university of Colombia. Faculty of Medicine, Institute of Public Health, Department of Public Health. Bogota Colombia (2014).

4. Gonzalez. "Canine fecalism, another problem of overflowing contamination" (2016).

5. Latorre E and Napoles M. "Study to determine contamination with canine zoonotic parasites in parks in the urban area of the metropolitan district of Quito, (Postgraduate thesis), Ecuador (2014): 6163.

6. Medina Rodriguez and Bolio. "Intestinal nematodes of dogs in public parks in Yucatan, Mexico (2018).

7. Merck. "The Merck Veterinary Manual". Spanish edition. Ocean publishing group, s.a. Fifth edition (2018).

8. Ministry of Public Health. Regulation of ownership and responsible management of dogs (2009).
9. MSP. Ministry of Public Health (2016).

10. WHO. Echinococcosis (2018).

11. Pena and Vidal. "Parasitic zoonoses caused by dogs and cats, aspect to consider in Public Health of Cuba (2017).

12. Pinheiro P. "Infectious disease.

13. Ramón G. "Prevalence of gastrointestinal helminths (cestodes and nematodes) in dogs from the city of Cuenca, Postgraduate thesis, Ecuador (2012): 86-90.

14. Rivera J. "Determination of the incidence of canine toxocariosis in the urban parish of the Baba canton, province of Los Ríos (2011).

15. Taranto N., et al. "Zoonotic parasites transmitted by dogs in the Chaco of Salta original article". Buenos Aires, A Medicina (B Aires) 60.2 (2000):217-220.

16. Uribarren T. "Visceral larva migrans. Mexico". Department of Microbiology and Parasitology, Faculty of Medicine, UNAM (2015).

17. Vasquez R., et al. "Prevalence of Toxocara Canis in the City of Popayán". University of Cauca, Colombia (2004).

\section{Assets from publication with us}

- Prompt Acknowledgement after receiving the article

- Thorough Double blinded peer review

- Rapid Publication

- Issue of Publication Certificate

- High visibility of your Published work

Website: www.actascientific.com/

Submit Article: www.actascientific.com/submission.php

Email us: editor@actascientific.com

Contact us: +919182824667 